\title{
LISTADO DE TESIS
}

\begin{tabular}{|c|c|c|c|c|}
\hline $\mathbf{N}^{\circ}$ & Autor(es) & Título & Año & Asesor \\
\hline $257 \mathrm{~A}$ & Gonzáles Vidal Alexander & $\begin{array}{l}\text { Análisis y Reflexiones en torno ala enseñanza del tenis } \\
\text { en niños de } 5 \text { años }\end{array}$ & II / 96 & Beatriz Puentes \\
\hline 258 & Guachetá R. Jorge & Educación Física por amor Propio & II / 96 & Ma. Teresa García \\
\hline 259 & Herrera William & $\begin{array}{l}\text { La infraestructura física de las actividades de } \\
\text { Educación Física en } 21 \text { colegios de educación } \\
\text { secundaria en el sector suroccidental de Santafé de } \\
\text { Bogotá }\end{array}$ & II / 96 & Efraín Serna \\
\hline 260 & $\begin{array}{l}\text { Mendoza Espinel Luz Helena } \\
\text { Pérez Rodríguez Tucidides }\end{array}$ & $\begin{array}{l}\text { Alternativas de cambio en el trabajo con niños de } 10 \text { a } \\
12 \text { años por intermedio del fútbol, siete en la escuela } \\
\text { colombiana de fútbol -ESCOFUTUPER- }\end{array}$ & II / 96 & Oscar Bernal \\
\hline 261 & Molina Florían Liliana & $\begin{array}{l}\text { La alimentación, una posibilidad para educar en el } \\
\text { espacio escolar }\end{array}$ & II / 96 & Gloria Jiménez \\
\hline 262 & Moreno Torres Olga Lucía & $\begin{array}{l}\text { La danza folclórica colombiana como medio de } \\
\text { utilización del tiempo libre en el club de tercera edad } \\
\text { del barrio El Remanso }\end{array}$ & II / 96 & \\
\hline 263 & Muñoz Rojas Dagoberto & $\begin{array}{l}\text { Propuesta de una educación para la vida teniendo } \\
\text { como elemento fundamental el amor }\end{array}$ & II / 96 & Gibson Useche \\
\hline 264 & Novack Bustamante Ricardo & $\begin{array}{l}\text { La actitud, un factor determinante en la formación del } \\
\text { deportista integral }\end{array}$ & II / 96 & Ma. Teresa García \\
\hline 265 & Osorio Gomez Juan Carlos & Jugar con la imaginación & II / 96 & Gibson Useche \\
\hline 266 & $\begin{array}{l}\text { Peña S. Alfonso } \\
\text { Riaño E. Zulma } \\
\end{array}$ & $\begin{array}{l}\text { El desarrollo de la autoestima también es tarea del } \\
\text { educador }\end{array}$ & II / 96 & Hernando Mosso \\
\hline 267 & Pinzón Díaz José Alonso & $\begin{array}{l}\text { Favoreciendo la comunicación, el respeto y la ayuda } \\
\text { mutua por medio de la educación Física una } \\
\text { experiencia con los niños en el centro comunitario } \\
\text { Lourdes. }\end{array}$ & II / 96 & Ana Belén ortega \\
\hline 268 & Pulido Herrera Marta Liliana & $\begin{array}{l}\text { La reflexión una critica de la realidad de la Educación } \\
\text { Física }\end{array}$ & II / 96 & $\begin{array}{l}\text { Marco Aurelio } \\
\text { Rodríguez }\end{array}$ \\
\hline 269 & Romero Cifuentes Manuel Bernardo & $\begin{array}{l}\text { Propuesta metodológica para la enseñanza- } \\
\text { aprendizaje del estilo mariposa en adultos mayores de } \\
\text { la Escuela de Deportes Acuáticos de la UPN. }\end{array}$ & II / 96 & $\begin{array}{l}\text { José María } \\
\text { Castellanos }\end{array}$ \\
\hline 270 & Salamanca Lopez Francisco Javier & $\begin{array}{l}\text { Relación cultural de la práctica del atletismo con los } \\
\text { procesos de formación en el adolescente. }\end{array}$ & II / 96 & Rafael Morales \\
\hline 271 & Salinas Mario & $\begin{array}{l}\text { Experiencia a través de la educación Física para } \\
\text { propiciar toma de decisiones. }\end{array}$ & II / 96 & $\begin{array}{l}\text { José María } \\
\text { Castellanos }\end{array}$ \\
\hline 272 & Sanabria Dueñas Olga Lucía & $\begin{array}{l}\text { El cuerpo en movimiento: Una vivencia imprescindible } \\
\text { en el preescolar hacia la construcción del esquema } \\
\text { corporal }\end{array}$ & II / 96 & Ana Belén ortega \\
\hline 273 & Sánchez Rodríguez Diego alonso & $\begin{array}{l}\text { El boxeo: Una nueva mirada(Experiencia adelantada } \\
\text { con los niños del Polideportivo Kennedy) }\end{array}$ & II / 96 & Julio Rodríguez \\
\hline 274 & Sosa Bermúdez Carlos Álvaro & $\begin{array}{l}\text { La Picota: Un lugar incierto y cautivante para el } \\
\text { educador físico. }\end{array}$ & II / 96 & Ana Belén ortega \\
\hline 275 & Suavita Bejarano José Reinel & $\begin{array}{l}\text { La danza folclórica colombiana como medio de } \\
\text { utilización del tiempo libre en el club del barrio El } \\
\text { Remanso. }\end{array}$ & II / 96 & $\begin{array}{l}\text { Miguel Ángel } \\
\text { Córdoba }\end{array}$ \\
\hline 276 & Torres Rojas Hugo Arturo & $\begin{array}{l}\text { Adecuación del ente deportivo municipal vigente Ley } \\
181 \text { del } 18 \text { de enero de } 1995\end{array}$ & II / 96 & $\begin{array}{l}\text { Judith palacios de } \\
\text { Jaramillo }\end{array}$ \\
\hline 277 & Truque Rivera William Augusto & $\begin{array}{l}\text { Desarrollo del respeto y la autoestima como proceso } \\
\text { de socialización en niños de } 12-16 \text { años del Internado } \\
\text { Hogar sagrada Familia a través del aprendizaje de los } \\
\text { fundamentos del baloncesto. }\end{array}$ & II / 96 & Álvaro Gracia \\
\hline 278 & Valdiri Suesca Gloria Elena & $\begin{array}{l}\text { La educación Física y la lectoescritura: Una } \\
\text { experiencia en el Colegio Isla del Sol. }\end{array}$ & II / 96 & Ana Belén ortega \\
\hline 279 & Villegas Rodríguez Orlando & $\begin{array}{l}\text { Una propuesta de replanteamiento en la orientación } \\
\text { del programa de Educación Física en las comunidades } \\
\text { indígenas, Guananas, Tucanas, desanas y Cubezanas } \\
\text { del Vaupés }\end{array}$ & II / 96 & Gibson Useche \\
\hline
\end{tabular}

